\title{
AVALIAÇÃO DO FLUXO RODOVIÁRIO CSN NA CIDADE DE VOLTA REDONDA*
}

\author{
Paulo Henrique da Silva Gomes ${ }^{1}$ \\ Eduardo Vinicius dos Santos ${ }^{2}$ \\ Ubaldo Marques Silva Filho ${ }^{3}$ \\ João Mário Lourenço Filho ${ }^{4}$
}

\begin{abstract}
Resumo
O tráfego rodoviário de cargas está em franco crescimento, se diversificando nas rodovias e também nos grandes centros urbanos. O uso de novos implementos (carretas maiores e com maior capacidade de carga) resulta no travamento das vias urbanas, causando grandes transtornos à população. Em muitas cidades, o tráfego exige um novo planejamento urbano e construção de vias alternativas. Em Volta Redonda, RJ, estão sendo desenvolvidos projetos com alternativas de fluxos rodoviários, que buscam soluções para o transporte coletivo, bem como, para fluxo de veículos pequenos, médios e de cargas da cidade. O fluxo de caminhões que abastecem e escoam os produtos da CSN - Usina Presidente Vargas, tendem a crescer com o aumento de produtividade da planta de Cimentos e startup da planta de Aços Longos, com início de suas operações em Janeiro/14. Alternativas como a intensificação do uso de ferrovia são foco do trabalho da área de logística da CSN, porém não eliminam o uso do modal rodoviário.
\end{abstract}

Palavras-chave: Fluxos rodoviários; Mobilidade urbana.

\section{ROAD LOAD FLOW EVALUATION IN THE CITY OF VOLTA REDONDA}

\begin{abstract}
The road freight traffic is rapidly growing and diversifying the highways and also in large urban centers. The use of new implements (larger trucks and greater load capacity) result in traffic jam of urban roads, causing great inconvenience to the people. In many cities, the traffic requires a new urban planning and construction of alternative routes and infrastructure. Projects in Volta Redonda city are being developed with alternative road flows, seeking solutions to public transportation as well as for flow small, medium vehicles and cargo city. The trucks flow that inbound and outbound CSN - Usina Presidente Vargas, located in Volta Redonda city tend to grow with the increased productivity of the cement plant and startup of Long Steel plant, with startup operations in January/14. Alternatives such as increased rail load are the focus of the work of logistics team CSN, but not terminated the use of road transport.
\end{abstract}

Keywords: Road flows; Urban mobility.

1 Administrador de Empresas, Analista de Logística, Companhia Siderúrgica Nacional, Volta Redonda, RJ, Brasil.paulo.gomes@csn.com.br.

2 Eng. Produção, Coordenador de Logística, Companhia Siderúrgica Nacional, Volta Redonda, RJ, Brasil. eduardo.santos@csn.com.br.

3 Administrador de Empresas, Gerente de Logística, Companhia Siderúrgica Nacional, Itaim Bibi, SP, Brasil. ubaldo@csn.com.br.

4 Eng. Mecânico, Diretor de Logística, Companhia Siderúrgica Nacional, Itaim Bibi, SP, Brasil. joao.lourenco@csn.com.br.

\footnotetext{
* Contribuição técnica ao 33० Seminário de Logística - Suprimentos, PCP, Transportes, 13 a 16 de maio de 2014, São Paulo, SP, Brasil.
} 


\section{INTRODUÇÃO}

A frota de veículos na cidade de Volta Redonda tem crescido a cada ano e como nos grandes centros urbanos esse aumento é consequência do aquecimento da indústria, do comércio e do poder aquisitivo da população. O ritmo no aumento de veículos nas ruas e estradas do município é maior que as ações de planejamento urbanístico, investimento em transporte público e utilização de novas alternativas de transporte, o impacto disso pode ser observado no excesso de veículos de pequeno, médio e grande porte em circulação nas cidades. Volta Redonda, no estado do RJ, é cortada por duas das principais rodovias brasileiras, a Rodovia Presidente Dutra (BR-116), que liga a cidade do Rio de Janeiro à cidade de São Paulo e a Rodovia Lúcio Meira (BR-393) que cruza a parte urbana de Volta Redonda com veículos da região Sul e estado de São Paulo com destino à região Nordeste do país, aumentando o volume de veículos nas vias da cidade, além de uma rodovia estadual a RJ-153, que liga o município ao Sul de Minas Gerais. Volta Redonda encontra-se no eixo ferroviário São Paulo - Rio de Janeiro - Belo Horizonte que atualmente é operado pela MRS Logística. Considerada uma das maiores produtoras de aço da América Latina, a CSN está expandindo seus negócios na área de cimentos e finalizando a implantação de uma nova fábrica de aços longos em Volta Redonda. Esse incremento de produção poderá aumentar a quantidade de veículos de grande porte em circulação nas principais vias urbanas da cidade, uma vez que um dos acessos à usina fica no bairro Aterrado, que possui uma grande concentração comercial e repartições públicas municipais, estaduais e federais, sendo considerado o centro administrativo da cidade. Buscando aumentar sua eficiência e contribuir com a redução no fluxo de veículos da cidade, a CSN vem desenvolvendo ações que permitam uma maior participação no modal ferroviário. O objetivo do trabalho foi analisar os possíveis impactos no abastecimento e escoamento do complexo Industrial Presidente Vargas, com algumas propostas de novos fluxos rodoviários que permitiriam uma melhora no trânsito da cidade de Volta Redonda.

\section{A LOGÍSTICA DA USINA PRESIDENTE VARGAS}

Localizada na cidade Volta Redonda, a Usina Presidente Vargas (UPV) é atualmente a maior usina integrada da América Latina, com uma capacidade anual de produção de 5,6 milhões de toneladas de aço bruto. Compõe ainda seu parque industrial uma fábrica de cimentos com capacidade anual de produção de 2,4 milhões de toneladas e uma fábrica de aços longos com capacidade anual de produção de 500 mil toneladas. Além desses volumes, ela recebe anualmente 15 milhões de toneladas de insumos. Para abastecer a usina e escoar os volumes de produção, a Usina Presidente Vargas utiliza o modal ferroviário composto pela MRS logística, responsável pelo eixo ferroviário São Paulo - Rio de Janeiro - Belo Horizonte e a VLi no corredor Minas Gerais - Rio de Janeiro. Juntas essas ferrovias movimentam $65 \%$ do volume de abastecimento e $35 \%$ do volume de escoamento da usina, tornando a CSN uma das maiores usuárias do modal ferroviário do país. O restante desse volume é movimentado através do modal rodoviário, em veículos de médio e grande porte. A CSN através de recursos próprios e em parceira com seus operadores logísticos desenvolve soluções para aumentar sua capacidade de movimentação através do modal ferroviário, o que permite uma maior eficiência em suas operações e de seus parceiros, garantindo assim uma redução no volume de caminhões em circulação na cidade de Volta Redonda e em outros municípios e

\footnotetext{
* Contribuição técnica ao $33^{\circ}$ Seminário de Logística - Suprimentos, PCP, Transportes, 13 a 16 de maio de 2014, São Paulo, SP, Brasil.
} 


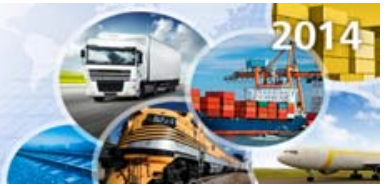

estados. A Figura 1 representa o esquemático em \% total das movimentações de 2013 da Usina Presidente Vargas.

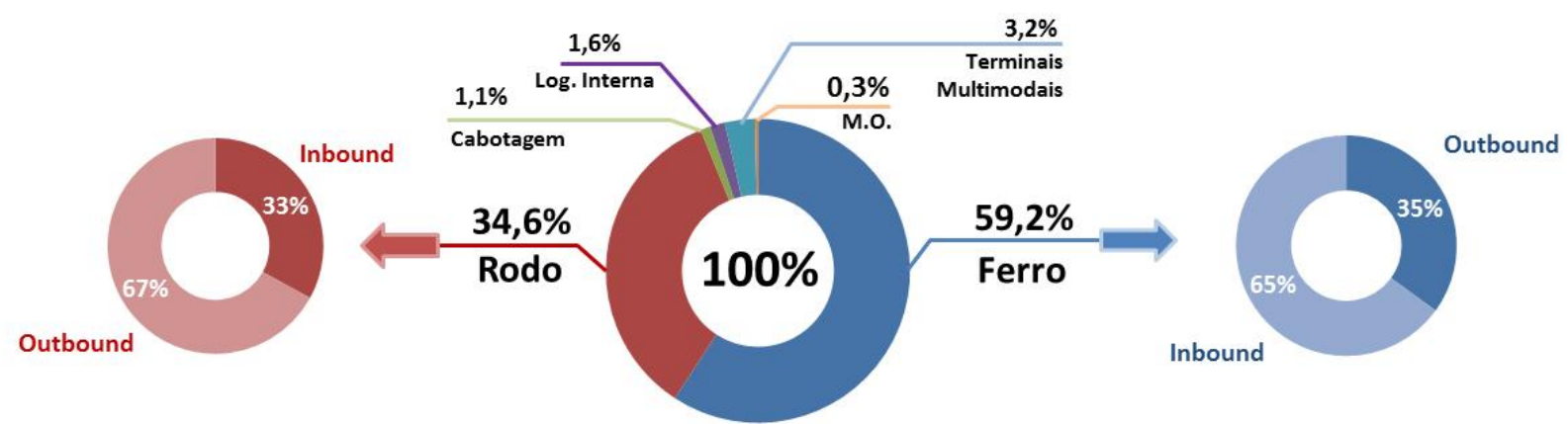

Figura 1. Porcentagem por modal movimentado pela Usina Presidente Vargas.

\subsection{Acesso de Caminhões à UPV}

Para atender suas operações, a Usina Presidente Vargas possui duas portarias de acesso, uma localizada na zona oeste, destinada para o escoamento de aços planos, aços longos e subprodutos gerados nos processos produtivos da usina e a segunda portaria localizada na zona leste destinada ao abastecimento de matériasprimas, insumos, itens de manutenção e materiais diversos para todos os negócios da usina. Ainda na zona leste fica localizada a expedição de cimentos, responsável por grande parte dos caminhões movimentados, conforme Figura 2.

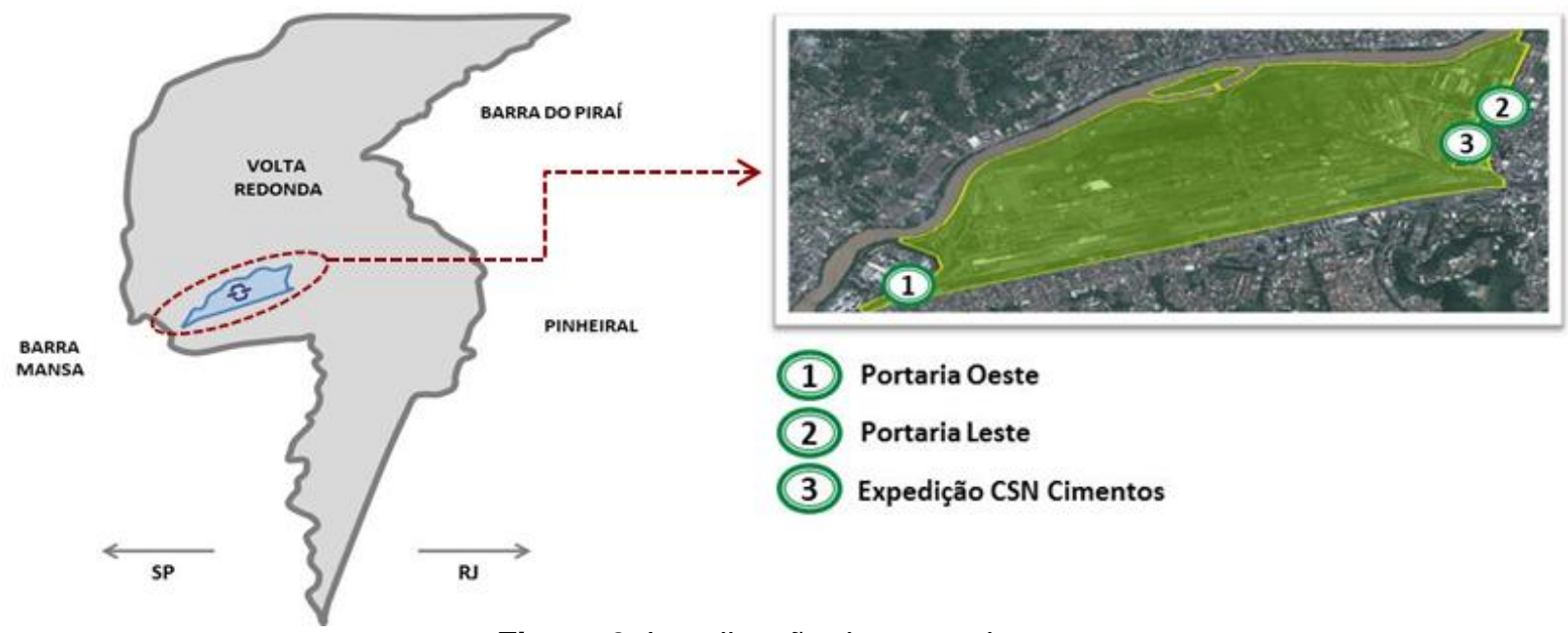

Figura 2. Localização das portarias.

\section{PRINCIPAIS ACESSOS RODOVIÁRIOS DA CIDADE DE VOLTA REDONDA}

A Cidade de Volta Redonda possui acesso à Rodovia Presidente Dutra (BR-116), que liga a cidade do Rio de Janeiro à cidade de São Paulo, a Rodovia Lúcio Meira (BR-393) que cruza a parte urbana de Volta Redonda com veículos da região Sul e estado de São Paulo com destino à região Nordeste do país, a RJ-153, rodovia estadual que liga o município ao Sul de Minas Gerais, a Rodovia dos Metalúrgicos (VRD-001), rodovia municipal com o objetivo de ligar o centro da cidade à Rodovia Presidente Dutra (BR116), além de outras vias que constam no planejamento do sistema viário municipal, conforme Figura 3.

\footnotetext{
* Contribuição técnica ao 33 Seminário de Logística - Suprimentos, PCP, Transportes, 13 a 16 de maio de 2014, São Paulo, SP, Brasil.
} 

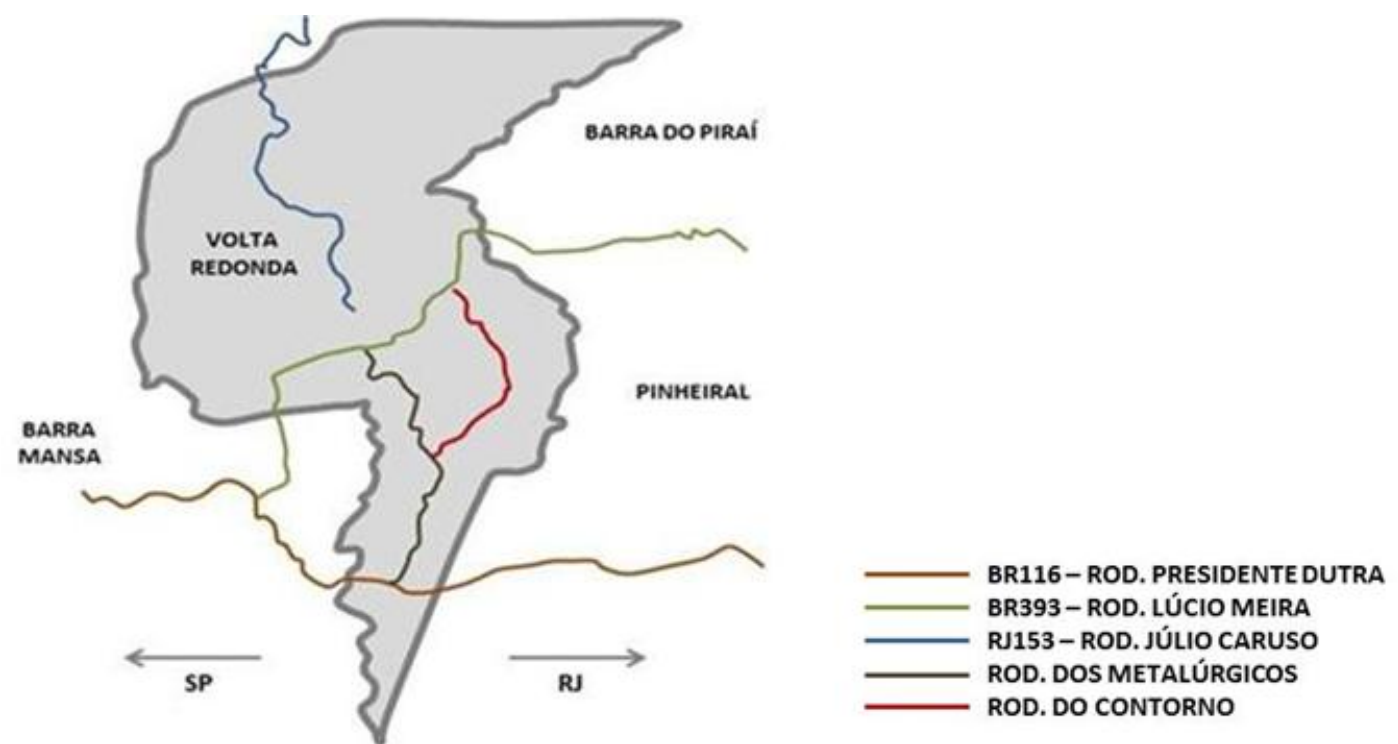

Figura 3. Principais acessos rodoviários da cidade de Volta Redonda.

\subsection{Concentração de Veículos na Área Central de Volta Redonda}

A área central da cidade de Volta Redonda possui uma grande concentração comercial e de repartições públicas e seus acessos são potencialmente prejudicados pelo excesso de veículos oriundos da Rodovia Lúcio Meira (BR393), que cruza a parte urbana (Figura 4), além de caminhões que utilizam as vias do centro da cidade para acessarem a zona leste da Usina Presidente Vargas.
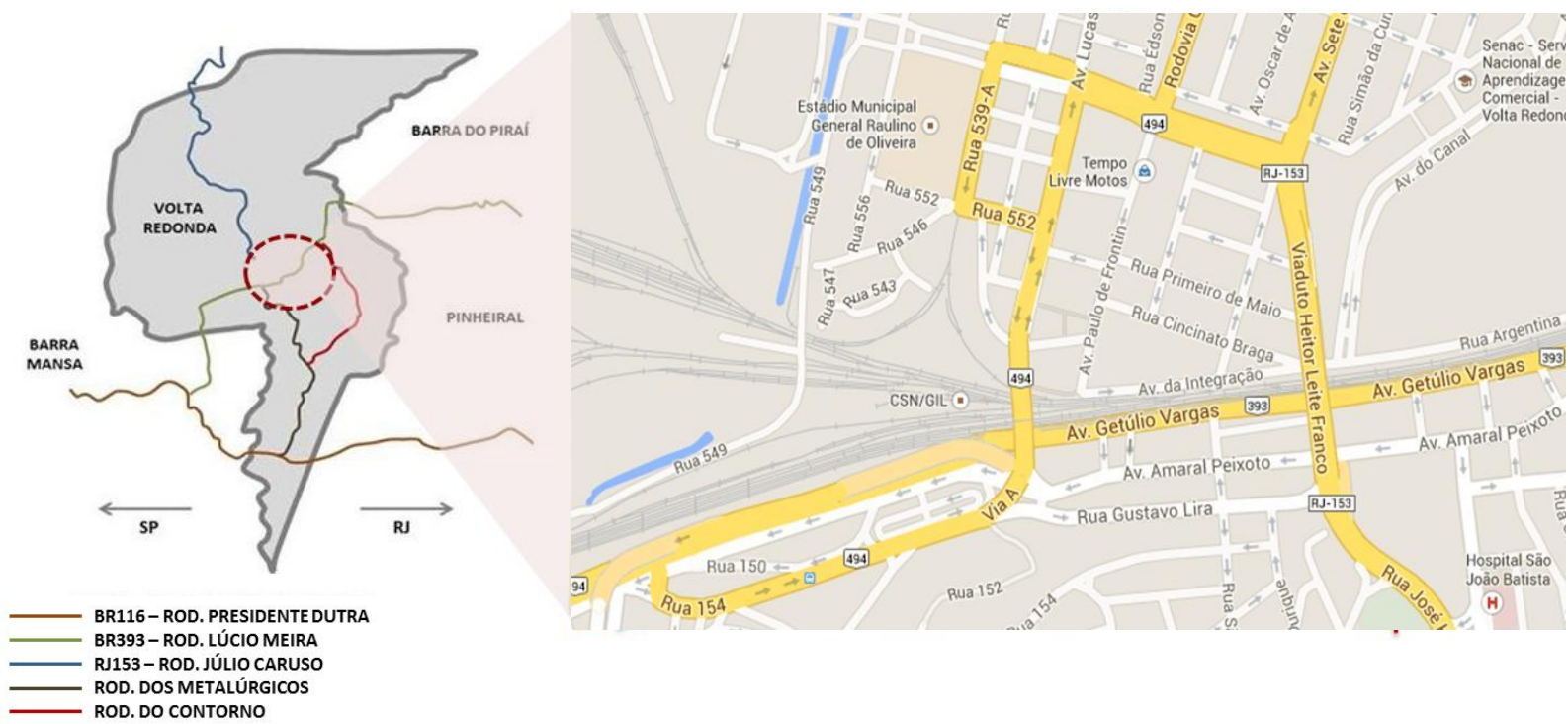

Figura 4. Localização da área central de Volta Redonda.

Para reduzir o impacto no volume de veículos que cruzam a parte central de Volta Redonda está sendo construída a Rodovia Nelson dos Santos Gonçalves, conhecida como "Rodovia do Contorno" que será uma continuação da BR-393 e terá como objetivo tirar o tráfego pesado de veículos que cortam a parte central da cidade.

\footnotetext{
* Contribuição técnica ao $33^{\circ}$ Seminário de Logística - Suprimentos, PCP, Transportes, 13 a 16 de maio de 2014, São Paulo, SP, Brasil.
} 


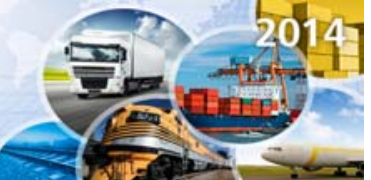

\section{MATERIAIS E MÉTODOS}

A metodologia utilizada para a realização desse estudo foi à pesquisa de campo que se baseia na observação dos fatos tal como ocorrem na realidade. De acordo com Andrade [1], essa metodologia tem por objetivo conseguir as informações e/ou conhecimentos sobre um problema para o qual se busca uma resposta ou de uma hipótese que se queira comprovar ou, ainda, descobrir novos fenômenos.

Os objetivos específicos do estudo de campo foram:

- Identificar, por portaria, a quantidade e os horários de entrada e saída dos caminhões da UPV;

- Apresentar os principais destinos dos caminhões da UPV à partir das portarias;

- Analisar a utilização do modal ferroviário da Usina Presidente Vargas nos últimos anos; e

- Avaliar o fluxo desenhado pela prefeitura para o tráfego de caminhões que acessam a portaria leste da usina.

As avaliações estatísticas, geradas através de captura dos dados do sistema de portaria da usina e também do sistema ERP - Enterprise Resource Planning, nos deu embasamento para conhecer os volumes, rotas e características técnicas operacionais, por consequência, seus efeitos na cidade. As alternativas atuais de chegada e saída de veículos rodoviários, bem como o percentual de vendas e distribuição dos diversos negócios nos direcionaram para a avaliação das possíveis soluções de fluxo.

\section{AVALIAÇÃO DO FLUXO RODOVIÁRIO}

\subsection{Identificação da Quantidade de Caminhões, Principais Horários e Rotas dos Caminhões da UPV}

Para atender a demanda da usina, são realizadas diariamente uma média de 2.032 viagens entre caminhões de pequeno, médio e grande porte. Na figura 5 é possível conhecermos a distribuição das viagens por portaria.

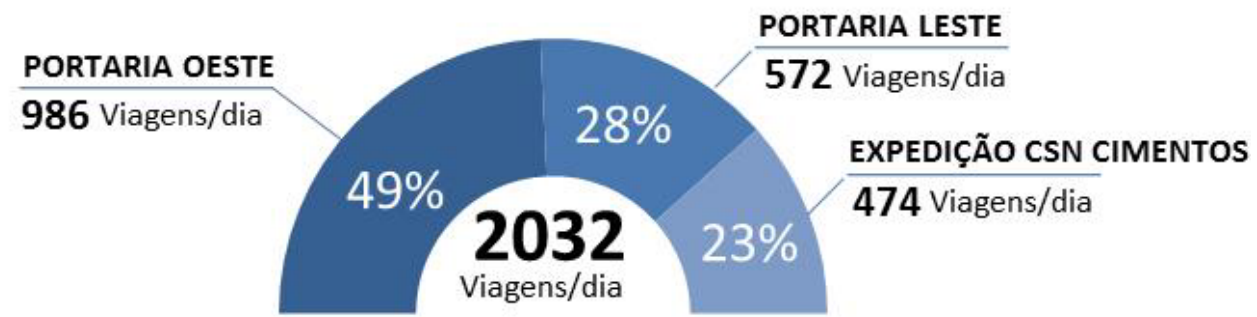

Figura 5. Distribuição das viagens por portaria.

Pode-se observar, na Figura 5, que a maior concentração de veículos está localizada na portaria oeste da UPV. Foi verificado o perfil dos caminhões que realizam o transporte para a UPV, os veículos foram divididos em: veículos com capacidade de até 14 toneladas, veículos com capacidades entre 14 e 27 toneladas e veículos com capacidade acima de 27 toneladas, conforme a Figura 6.

\footnotetext{
* Contribuição técnica ao 33o Seminário de Logística - Suprimentos, PCP, Transportes, 13 a 16 de maio de 2014, São Paulo, SP, Brasil.
} 


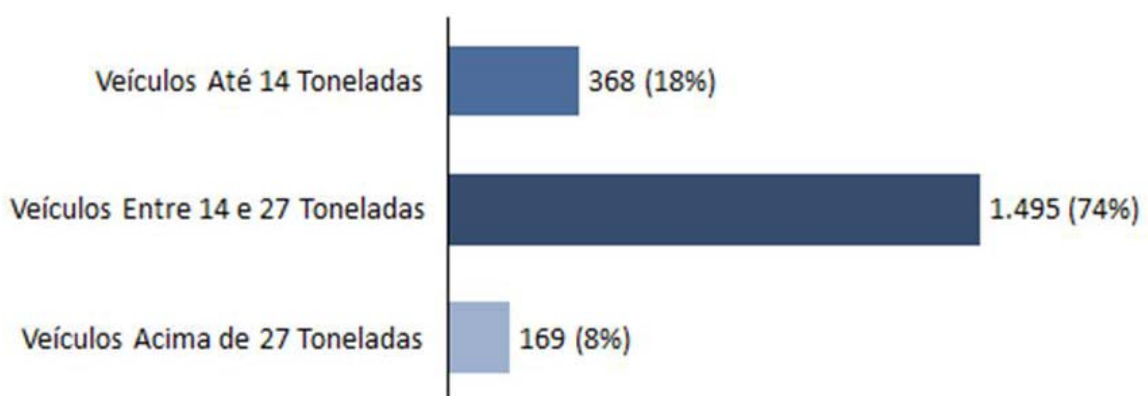

Figura 6. Perfil dos caminhões.

A entrada e saída desses veículos acontecem 24 horas por dia, sete dias na semana, e esse acesso pode variar de acordo com perfil, criticidade e por tipo de produto, conforme pode ser visto na Figura 7.

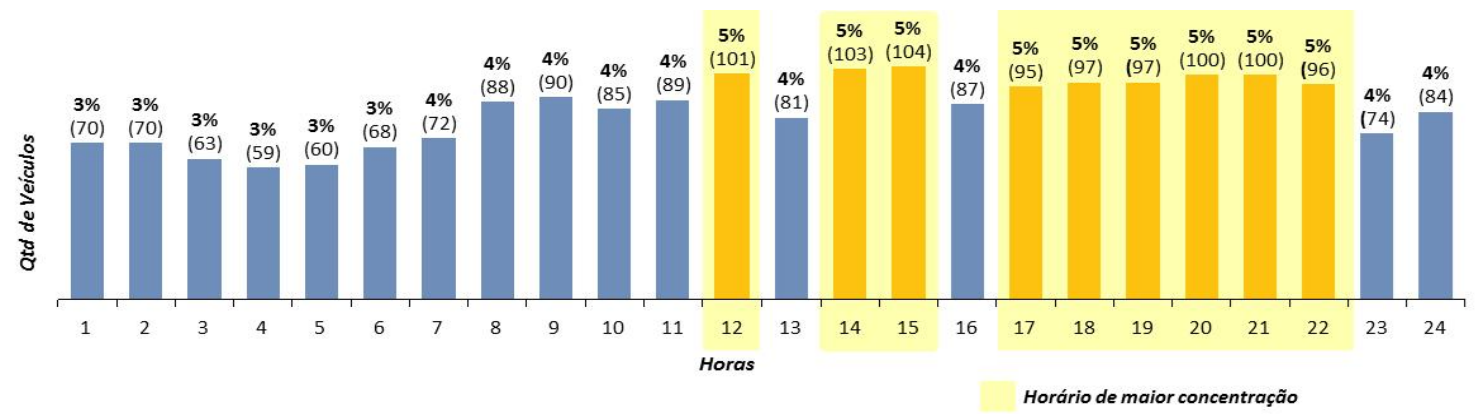

Figura 7. Horários de acesso à UPV.

Mesmo com alguns horários de maior concentração dos veículos é possível observar que existe uma linearidade nos horários, o que contribui para que não ocorra um acúmulo de veículos nos horários de pico da cidade.

Para observar o comportamento individual de cada portaria, foi realizada uma análise por portaria para identificar à concentração de caminhões durante o dia.

\subsubsection{Portaria oeste}

Responsável pelo escoamento de aços planos, aços longos e subprodutos gerados nos processos produtivos da usina, apresenta uma distribuição com picos nos horários de almoço e após as 18h. Conforme pode ser visto na Figura 8.

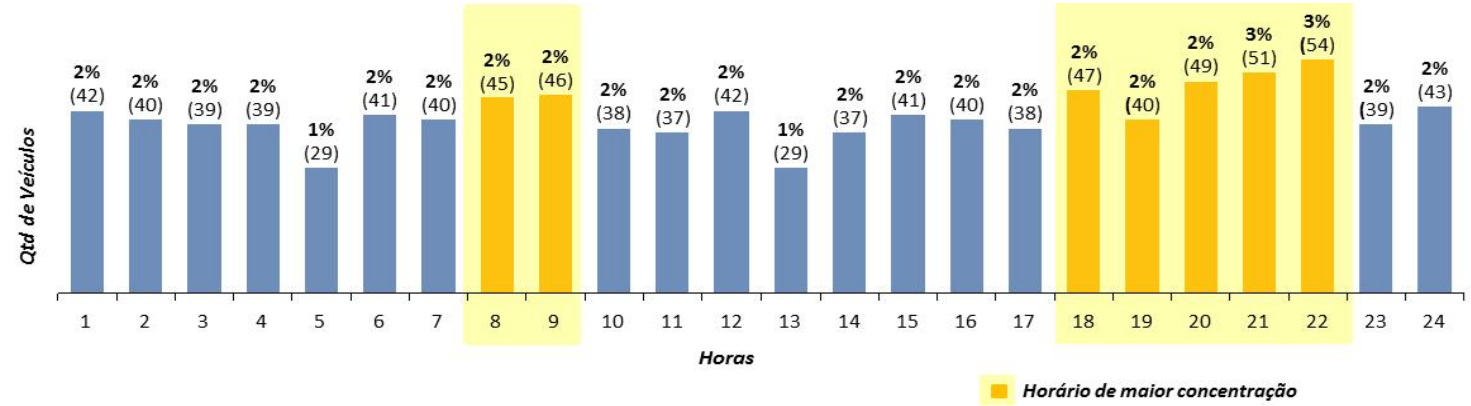

Figura 8. Horários de acesso à UPV via portaria oeste.

Mesmo com uma pequena variação entre as $20 \mathrm{~h}$. e $22 \mathrm{~h}$., a portaria oeste apresenta uma linearidade em sua utilização.

\footnotetext{
* Contribuição técnica ao $33^{\circ}$ Seminário de Logística - Suprimentos, PCP, Transportes, 13 a 16 de maio de 2014, São Paulo, SP, Brasil.
} 


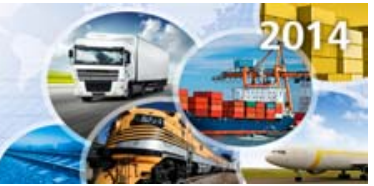

\subsubsection{Portaria leste}

Responsável pelo abastecimento de matérias-primas, insumos, materiais de manutenção e materiais diversos para todos os negócios da usina, possui maior movimentação entre 12h. e 15h., e depois das 19h. as 21h., conforme Figura 9.

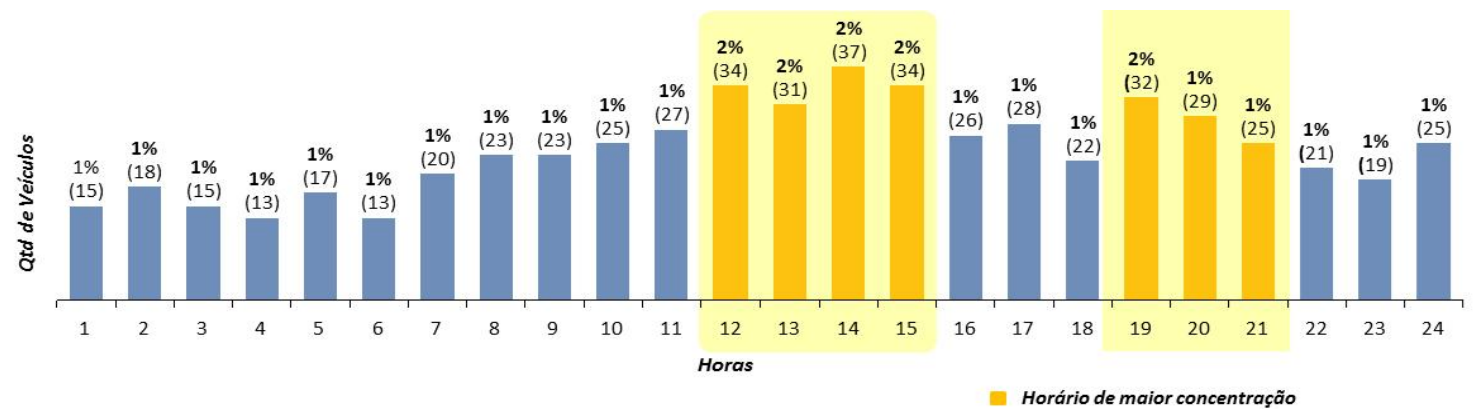

Figura 9. Horários de acesso à UPV via portaria leste.

A portaria leste apresenta uma baixa utilização entre $1 \mathrm{~h}$. e $7 \mathrm{~h}$. da manhã.

\subsubsection{Expedição de cimentos}

Responsável pelo recebimento de caminhões de embalagem (paletes) e escoamento da produção da fábrica de cimentos, possui maior movimentação entre 11h. e 21h., conforme Figura 10.

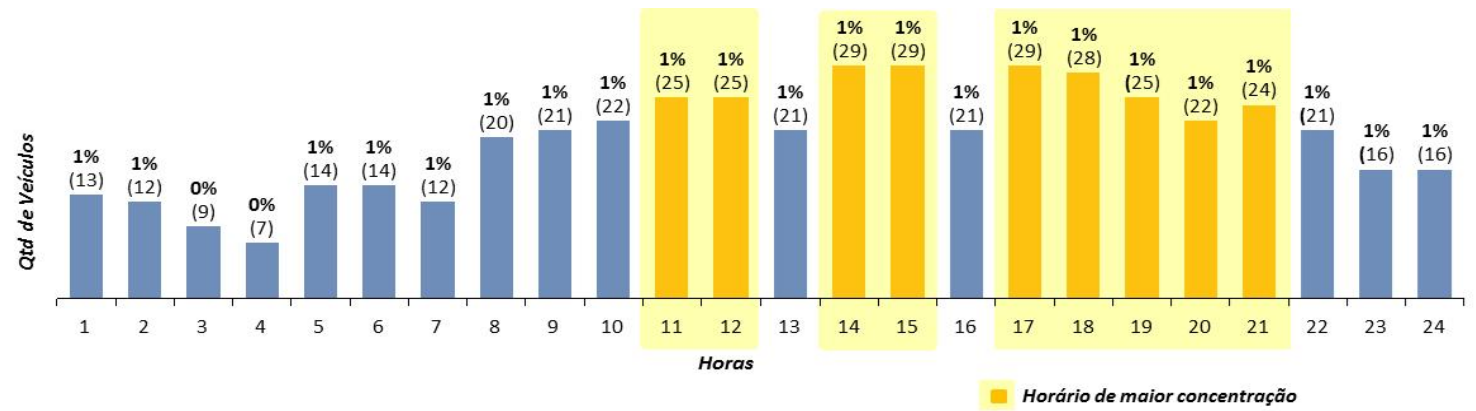

Figura 10. Horários de acesso à UPV via expedição de cimentos.

A expedição de cimentos apresenta uma baixa utilização entre 1h. e 7h. da manhã.

\subsection{Principais Destinos dos Caminhões da UPV por Portaria}

Foi realizado um mapeamento dos principais destinos dos caminhões, a partir das portarias, com o objetivo de analisar o volume de tráfego nas principais rotas da cidade.

Os principais destinos dos caminhões que utilizam a portaria oeste foram conforme demonstra a Figura 11. 


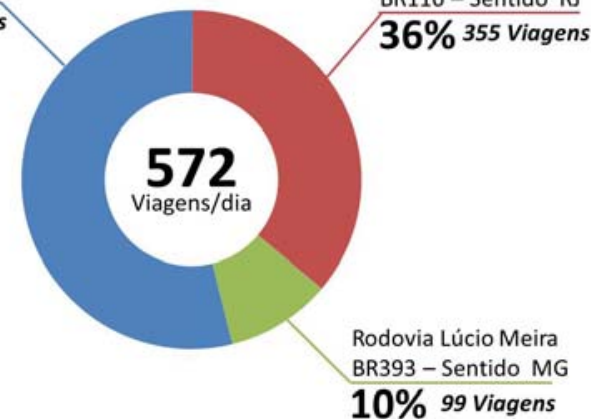

Figura 11. Destino dos caminhões da portaria oeste.

A portaria oeste possui uma grande concentração de veículos com destino à Rodovia Presidente Dutra, sentido São Paulo.

Os principais destinos dos caminhões que utilizam a portaria leste foram conforme demonstra a Figura 12.

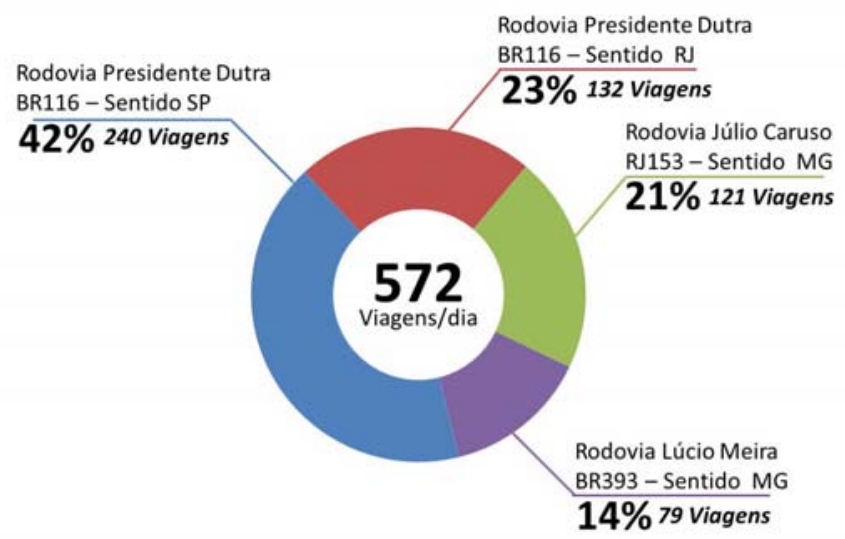

Figura 12. Destino dos caminhões da portaria leste.

A portaria leste possui uma grande concentração de veículos com destino à Rodovia Presidente Dutra, sentido São Paulo.

Os principais destinos dos caminhões que utilizam a expedição de cimentos foram conforme demonstra a Figura 13.

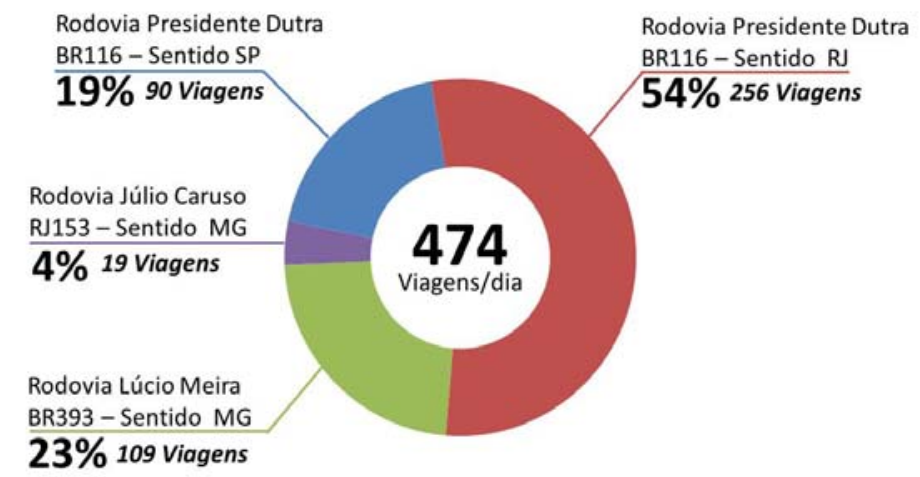

Figura 13. Destino dos caminhões da expedição de cimentos.

A expedição de cimentos possui uma grande concentração de veículos com destino à Rodovia Presidente Dutra, sentido a cidade do Rio de Janeiro RJ.

\footnotetext{
* Contribuição técnica ao $33^{\circ}$ Seminário de Logística - Suprimentos, PCP, Transportes, 13 a 16 de maio de 2014, São Paulo, SP, Brasil.
} 


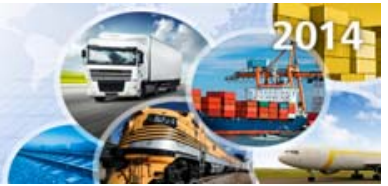

Através do mapeamento dos principais destinos, foi possível observar que o maior volume de caminhões se concentra na entrada oeste da cidade que utiliza a BR393, trecho conhecido como "207", por ser este o principal acesso dos caminhões à rodovia Presidente Dutra. A Figura 14 demonstra o grau em cores da utilização dos veículos CSN dos principais eixos de acesso da cidade de Volta Redonda.

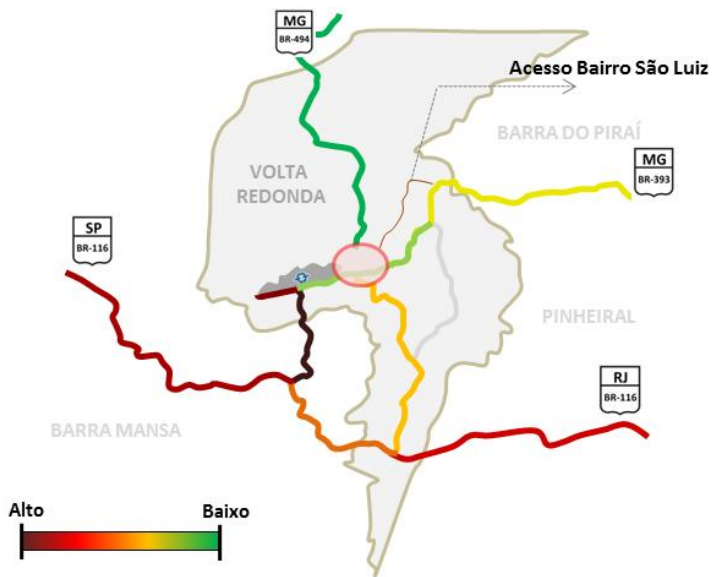

Figura 14. Concentração de caminhões CSN nos principais acessos rodoviários de Volta Redonda.

\subsection{Utilização do Modal Ferroviário Para a Redução no Volume de Caminhões}

Considerada uma das maiores empresas usuárias da ferrovia no país, a CSN vem desenvolvendo estudos para aumentar sua capacidade de movimentação de cargas através do modal ferroviário. Realizando ações próprias ou em parceria com seus operadores logísticos, a companhia vem aumentando constantemente a utilização da ferrovia nos últimos anos o que contribui para a redução considerável do número de caminhões nas vias urbanas da cidade. O resultado dessa ação já faz com que a CSN seja a maior usina siderúrgica brasileira que utiliza o modal ferroviário em suas operações. A empresa ainda possui uma meta agressiva para chegar a $50 \%$ de suas movimentações de outbound no modal ferroviário.

O uso intensificado da ferrovia garante ainda uma redução de emissão de $\mathrm{CO}_{2}$, já que retira uma grande quantidade de veículos rodoviários das estradas brasileiras, sendo este outro grande objetivo da CSN.

Importante destacar que a quantidade de caminhões utilizados pela Usina Presidente Vargas não aumentou se comparado com o aumento da produtividade e entrada de novos negócios em seu parque industrial, mas a empresa segue com sua meta de aumentar o uso da ferrovia ao máximo em suas operações.

\subsection{Proposta de Fluxo Rodoviário Apresentado pela Prefeitura para o Tráfego de Caminhões}

Apesar de um grande volume de veículos que acessam a portaria oeste da Usina Presidente Vargas, os caminhões que circulam por essa área não impactam no fluxo das principais vias urbanas do município, dessa forma as ações da prefeitura estão sendo concentradas na área central da cidade. O estudo da prefeitura apresenta alternativas para o transporte de caminhões e busca reduzir o fluxo de veículos pesados nas principais vias do centro da cidade. Isso é demonstrado na Figura 15.

\footnotetext{
* Contribuição técnica ao 33o Seminário de Logística - Suprimentos, PCP, Transportes, 13 a 16 de maio de 2014, São Paulo, SP, Brasil.
} 

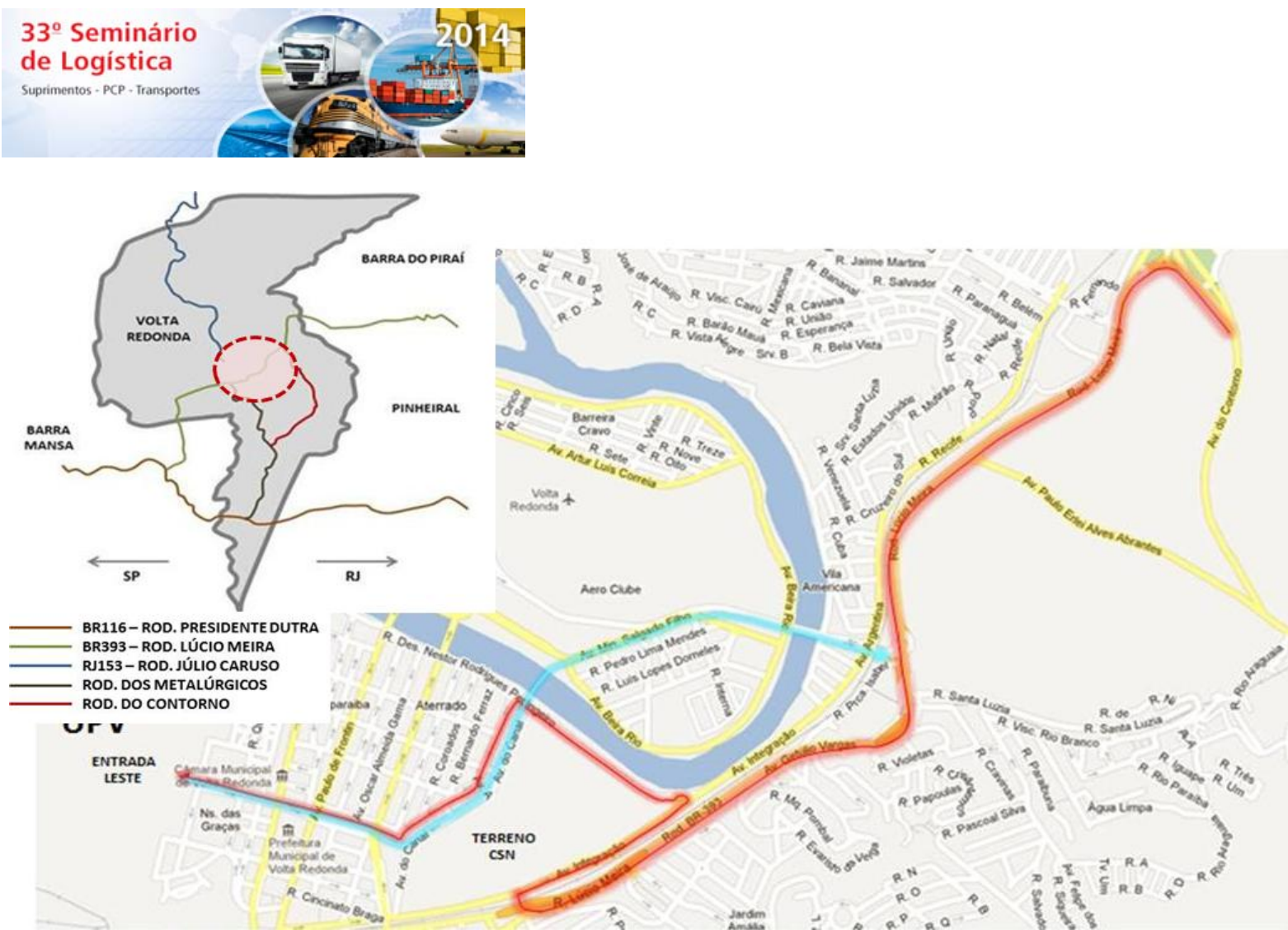

Figura 15. Novo fluxo rodoviário para caminhões que acessam a Usina Presidente Vargas pela zona leste.

Para o desenvolvimento desse estudo a prefeitura considera a construção da Rodovia Nelson dos Santos Gonçalves (Rodovia do Contorno) como concluída. Os caminhões com sentido ao centro deverão seguir pela Rodovia Lúcio Meira (BR393) até o viaduto que ligará a BR393 com a Avenida Integração, os veículos seguirão pela Avenida Integração onde deverão acessar a Rua Nestor Rodrigues Perlingeiro passando em frente ao novo fórum da cidade, depois utilizarão a Avenida do Canal onde será criado um corredor para caminhões que cruzará a cidade até o acesso leste da Usina Presidente Vargas, passando em frente à prefeitura e ao estádio municipal. Os caminhões que estiverem realizando o fluxo de saída da CSN deverão utilizar o corredor de caminhões até a Avenida do Canal, onde será criada uma ponte sobre o rio Paraíba do Sul, que fará o acesso dos caminhões até a Avenida Ministro Salgado Filho, depois os veículos seguirão até o acesso à Rodovia Lúcio Meira (BR393) podendo utilizar a Rodovia Nelson dos Santos Gonçalves (Rodovia do Contorno), para acessarem a Rodovia Presidente Dutra.

\section{RESULTADOS}

\subsection{Novo Fluxo Rodoviário}

Após avaliações entre a proposta feita pela prefeitura e resultados obtidos da pesquisa operacional da CSN, foi desenhado um fluxo que visa ser mais eficiente reduzindo os custos de construção e eliminando a passagem dos veículos em frente ao novo fórum da cidade. Este estudo será apresentado à prefeitura para discussão e avaliação da oportunidade de implantação conforme pode ser visto na Figura 16.

\footnotetext{
* Contribuição técnica ao 33 Seminário de Logística - Suprimentos, PCP, Transportes, 13 a 16 de maio de 2014, São Paulo, SP, Brasil.
} 

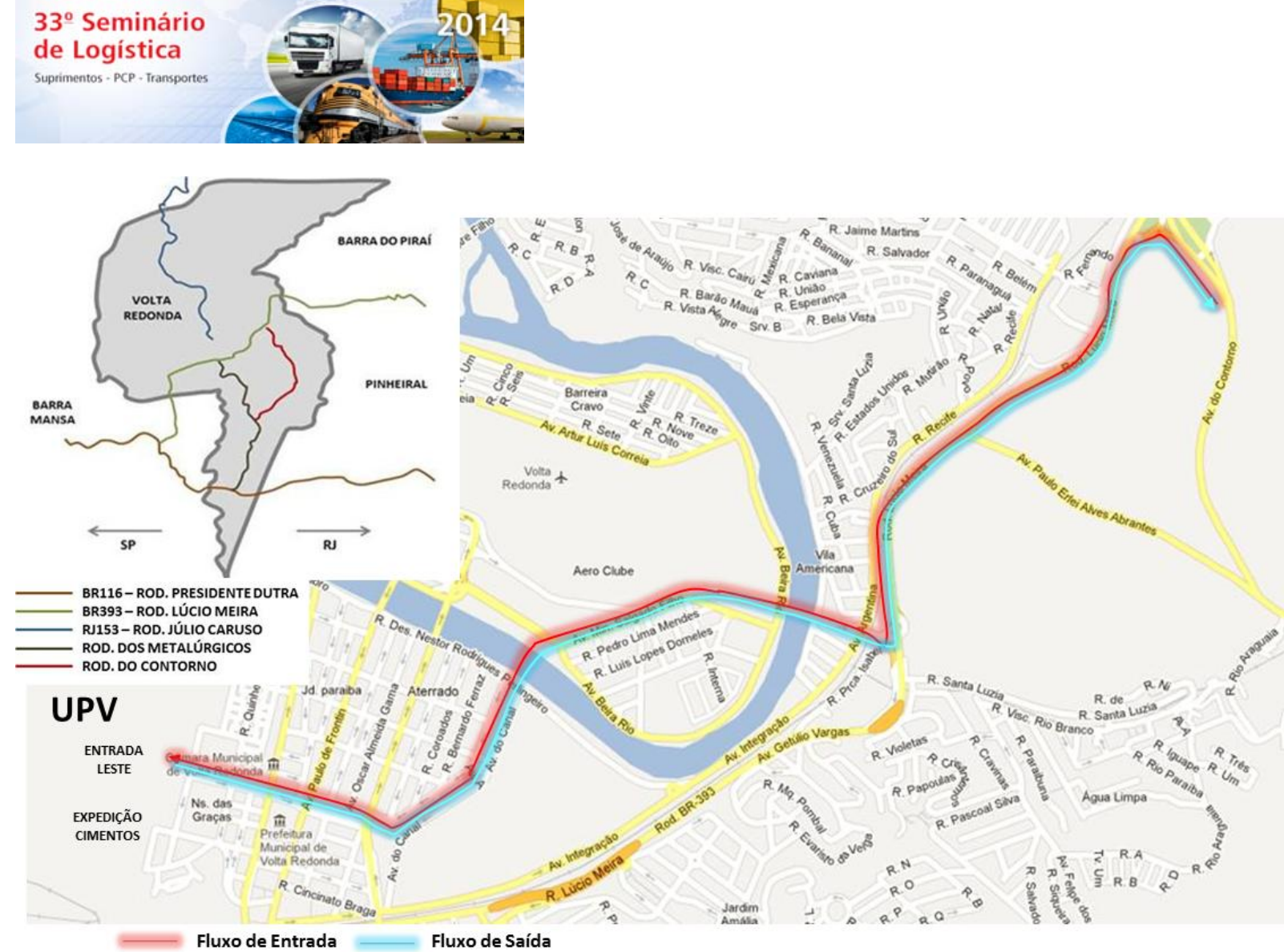

Figura 16. Novo fluxo de caminhões.

Através desse fluxo, os veículos utilizarão um mesmo trajeto para entrar e sair do centro da cidade não sendo mais necessário a construção de um viaduto sobre a linha férrea. O corredor de caminhões foi mantido próximo à prefeitura e o estádio municipal e para a implementação desse projeto será necessário a construção de um novo trevo de acesso à Rodovia Lúcio Meira (BR393) e a finalização das obras da Rodovia do Contorno. Essas obras permitirão a passagem de veículos de grande porte, melhorando a mobilidade atual e eliminando a passagem desses veículos no centro comercial da cidade.

\section{DISCUSSÃO}

A busca incessante pela melhoria contínua faz com que empresas como a CSN desenvolvam iniciativas que garantam uma operação cada vez mais eficiente e sustentável. Estudar melhores formas de armazenagem, movimentação e distribuição de produtos em um mercado cada vez mais competitivo é fator fundamental de sucesso para uma empresa. Apenas ações da iniciativa privada não irão resolver o problema, é preciso que os órgãos públicos municipais, estaduais e federais invistam no planejamento urbano de suas cidades. As ações realizadas nos últimos anos pelo governo em planejamento urbanístico, transporte público, infraestrutura e iniciativas fiscais para a renovação de frota de veículos e utilização de novos modais, não seguiu a mesma velocidade do desenvolvimento do país, conclusão disto é uma ineficiência do transporte público e de cargas, estradas em más condições e uma frota de veículos sucateada.

O Brasil possui um potencial muito grande para explorar outros modais e melhorar os atuais, é preciso desenvolver estudos que garantam um transporte de qualidade com um baixo custo, seja de pessoas ou de cargas. O transporte eficiente contribui diretamente com a redução de $\mathrm{CO}_{2}$ na atmosfera e consumo energético, o que irá refletir diretamente na qualidade de vida da população, da mesma forma que a

\footnotetext{
* Contribuição técnica ao 33 Seminário de Logística - Suprimentos, PCP, Transportes, 13 a 16 de maio de 2014, São Paulo, SP, Brasil.
} 
eficiência no transporte contribuirá para reduzir o custo de produção das empresas, tornando o preço de nossos produtos mais competitivos frente a outros países.

A CSN entende que as alternativas apresentadas solucionam o problema de tráfego atual, porém não eliminam completamente o problema, já que o crescimento urbano e da frota brasileira cresce numa proporção muito maior aos investimentos em infraestrutura. É necessário que o governo federal continue com seu plano de investimento em ferrovia e rodovia para que num futuro seja possível chegar a um share ferroviário de $100 \%$. Foi avaliado que a CSN possui infraestrutura de carregamento em sua unidade em Volta Redonda para tal, o que necessita é termos mais destinos e terminais ferro-rodo preparados para essas operações. Os custos logísticos também devem ser reduzidos para que seja possível que a indústria nacional se mantenha nos mesmos patamares de competição com o mercado internacional.

\section{REFERÊNCIAS}

1 Andrade MM. Introdução à metodologia do trabalho científico: elaboração de trabalhos na graduação. $4^{\mathrm{a}}$ ed. São Paulo: Atlas; 1998.

\section{BIBLIOGRAFIA}

1 Ballou RH. Gerenciamento da cadeia de suprimentos/logística empresarial. $5^{\mathrm{a}}$ ed. Porto Alegre: Bookman; 2006.

2 Barat J. Logística e transporte no processo de globalização: oportunidades para o Brasil. São Paulo: Unesp; 2007.

3 Barat J. Logística, transporte e desenvolvimento econômico - volume i: a visão histórica. São Paulo: CLA; 2007.

4 CSN: Companhia Siderúrgica Nacional [página da internet]. Volta Redonda: CSN [acesso em 30 jan. 2014]. Disponível em: http://www.csn.com.br.

5 Prefeitura de Volta Redonda [página da internet]. Volta Redonda: Prefeitura de Volta Redonda [acesso em 8 jan. 2014]. Disponível em: http://www.portalvr.com/.

6 Ministério dos Transportes [página da internet]. Ministério dos Transportes [acesso em 13 jan. 2014]. Disponível em: http://transportes.gov.br/. 